\title{
HIGHER EDUCATION: SUSTAINING THE FUTURE OF STUDENTS DURING A PANDEMIC
}

\author{
Naziema Jappie \\ Centre for Educational Testing for Access \& Placement, University of Cape Town (South Africa)
}

\begin{abstract}
The COVID-19 challenge is unprecedented; its scale still is not fully understood. Universities in the South Africa do have plans in place to continue the academic year in 2021 but have no idea to what extent education will resume to normal face to face activity. Although the future is unpredictable, given the uncertainty in the epidemiological and economic outlooks, universities have to ensure quality and sustainability for the medium and long-term implications for teaching, learning, the student experience, infrastructure, operations, and staff.

Amongst the range of effects that COVID-19 will have on higher education this year, and possibly into future years, admission arrangements for students is one of the biggest. It is also one of the most difficult to manage because it is inherently cross sector, involving both schools and higher education. There is no template in any country of how to manage education during the pandemic. However, there are major concerns that exist, in particular, regarding the impact on learners from low income and disadvantaged groups. Many are vulnerable and cannot access the digital platform.

Post 1994, the South African government placed emphasis on the introduction of policies, resources and mechanisms aimed at redressing the legacy of a racially and ethnically fragmented, unjust, dysfunctional and unequal education system inherited from apartheid. Many gains were made over the past two decades especially, in higher education, two of which were access and funding for the disadvantaged students to attend university. However, the pandemic in 2020 disrupted this plan, causing the very same disadvantaged students to stay at home without proper learning facilities, poor living conditions or no access to devices and data. The paper argues that the tensions and challenges that dominated the Covid-19 digital educational reform have resulted in a significant paradigm shift focused on out of classroom experiences as expressed in the new ways of teaching and learning and possibly leaving certain groups of students behind.

Consideration is given to three broad areas within higher education in South Africa. Firstly the current dilemma of teaching and learning, secondly, the access or lack thereof to the digital platform and challenges facing students, and the thirdly, the issue of admission to higher education.

All three areas of concern represent the degree to which we face educational disruption during the pandemic.
\end{abstract}

Keywords: Access, digital learning, equality, sustainability, teaching.

\section{Introduction}

The Coronavirus, COVID-19 challenge is unprecedented. The complexity and instability of the education system was put to test and educational leaders had to make decisions that would have to take all matters into consideration. Schools and universities had to shut their doors and stop teaching and learning, students had to vacate their accommodation on campuses and return home. Most affected were foreign students who could not leave due to travel restrictions and had to find alternate accommodation. Education was brought to a complete halt - universities became empty shells, little ghost towns. Universities in South Africa are still closed in 2021, with very few classes that being conducted face to face. For now, teaching online is predominant and no one knows when normal activities will resume. But even though the higher-education sector does not have all the answers, given the uncertainty in the epidemiological and economic outlooks, they have questioned the medium- and long-term implications for teaching, learning, the student access to digital platforms and new admissions. This paper highlights the important issues that arose in higher education during the peak of the pandemic and includes some observation of the desktop research findings conducted by JET Education Services on Governance and Management-Higher Education Response to Covid-19. 


\section{Methodology}

The desktop research took place under exceptional circumstances, where face-to-face interviews and focus groups were impossible but where websites could be used to gather information and data for debate and discussion. The researchers adjusted to these new circumstances by flexibly and creatively investigating and categorising the varying responses by higher education institutions to the pandemic and the lockdown, in the process also drawing upon their own ideas and individual experiences. The research team consisted of 11 participants from a range of South African higher education institutions; they consisted mostly of young researchers and were accompanied by a team lead, a co-researcher and a reviewer.

Team meetings were held during the month of April using Google Hangouts as well as WhatsApp. There were also one to one discussions between the team lead and individual participants. The initial meeting set the scene for the work and divided the areas of interest among the participants. Each researcher was given a timeframe within which they were to complete the task given to them and submit their work on the Google platform created by JET. Report for theme 8 can be viewed at www.jet.org.za.

\section{Observations}

\subsection{Impact on teaching and learning}

The only certainty is uncertainty. However, given the mission, and operations of universities, they needed to examine all the possibilities across the institutions and the implications for teaching and learning. During the pandemic, it was envisioned that most students will complete the 2020 academic year online, and the class of 2020 will graduate virtually. Although the year was extended into 2021, some students were allowed to return to class for the second semester, especially if they were in their final year or needed to conduct laboratory work. However, restrictions remained for some international students and those who could reside in student accommodation were given resources to continue their studies.

Even this relatively optimistic outlook was likely to pose significant challenges to higher education. As South Africa decreed total strict lockdown from the COVID-19 pandemic in March 2020, the number of universities rapidly switching to emergency remote learning soared. However, few of the institutions were well prepared for this sudden, disruptive move, whilst others had a late start to the academic year. (Bevin et al, 2020). Much scrambling and improvisation occurred as the leadership, teaching staff and administrators made great strides to implement broad-based online remote teaching. University core task teams worked long hours to secure laptops for disadvantaged students and data from service providers to ensure that all students had the resources that they needed for the remote teaching to take place.

Remote or online teaching and learning is not the norm at South African universities. Staff and students had to reimagine the classroom virtually and engage without any face to face interaction. There was definitely a need for capacity building among academics so that they were sufficiently trained to offer virtual teaching. Some universities struggled with financing the systems for online learning. The system is extremely expensive, with a license fee of R4 million per year, said the DVC Academic Prof Crafford. Another challenge with regard to online learning is the issue of policies for facilitating teaching and assessment online. Minister Nzimande noted that only $20 \%$ of technical and vocational education and training (TVET) colleges can afford online education. (Timeslive, 2020). Many universities do not have the policies thus creating the need for serious policy development and implementation for the new normal. The national department of education (DHET) offered support for student in financial distress to ensure their stability in learning and mindset.

This pandemic exposed the inequalities and disparities in the higher education across the world and South Africa is no different. Universities began creating well-designed, sophisticated solutions for remote teaching/online learning but did not think seriously think about ways of addressing the issues for those who don't have access to internet even though they have been given data and laptops. The penny only dropped when the students complained. Increasingly, the more resourceful universities partnered with internet providers and governments to overcome this critical challenge by negotiating zero-rated access to specific educational and information websites, whilst other, less resourceful universities, desperately tried to remain financially sustainable. The scramble to teach remotely is one of the key challenges facing staff and students of a number of universities. Many higher education institutions have students from lower-socio economic backgrounds who do not have access to internet due to affordability. There was also a recognition that living conditions of many students are unconducive to learning, with overcrowded homes, insufficient amenities that would make it impossible for them to function suitably (USAF, 2020). 
It was vital and necessary to seriously seek alternative means and approaches in order not to leave behind students with little or no access to electronic communication. The painful reality of the digital divide in South Africa had to be strategically and systematically managed: reaching out to 'marginalised' students must be a national priority in this time of crisis. The shift to the "new normal" had to be sector wide with an emerging paradigm of how to reimagine education post COVID-19. The Universities South Africa (USAf) board members stated that majority of students are not ready to switch completely to online learning (USAF, 2020). Members engaged in a robust debate over the impact of the pandemic on the academic programme. While some reported a $90 \%$ readiness to deliver classes online, and some even declare that they were prepared to resume classes online from the as early as 1 April 2020, others urged a serious introspection over how the sector might ensure that all of its students were able to study, virtually (USAF, 2020).

\subsection{Quest for admission - Class of 2021!}

High school grade 12 learners in their final year, seek admissions to universities. With Grade 12 students back to school, a sense of optimism has grown, as well as prospects for a fresh start at university in 2021 and possibly 2022. But the calamitous, impact of COVID-19 on every facet of societal normality, means that the class of 2020 will have a variety of additional challenges to overcome should they want to study further.

COVID-19 will have an enormous impact on higher education, possibly for years ahead, especially on admission arrangements for incoming students. It is also one of the most difficult to manage because it involves both basic education i.e. schools and the higher education sectors. There is no template of how to deal with this and each country is doing the best they can. In South Africa in particular, there are major concerns regarding the impact on learners from low income and disadvantaged groups. (Atherton, 2020)

The principles and values enshrined in the SA Constitution, the Higher Education Act of 1997, and the White Paper for Transformation (1997) address the legacy of racial, gender, class and other forms of social discrimination imposed by apartheid. Matsepe et al (2020:437) show that universities tend to privilege students from rich or affluent communities while neglecting talented and potentially good students from marginalised groups, particularly those from under-resourced township and rural schools. In the reading is shows that the problem has shifted largely from race to one of social class due to an overemphasis on narrow conceptions of merit that cannot be reconciled with equity and social justice concerns. If this is the case under normal circumstances what then, is the impact on these marginalised students during the pandemic and will this create an opportunity for universities to rethink their admissions policies so that students from marginalised backgrounds have equal opportunity to enter higher education?

While there is sufficient evidence that most institutions agreed on the need to embrace the "no student left behind" motto, they have to address current social injustices, given the intensity of competition among institutions, and develop admission strategies that will allow the marginalised students access to higher education. The pandemic exacerbates the situation for disadvantaged students to benefit previous admissions policies, they require comparable skills, knowledge and resources with students from affluent backgrounds who have the ability to engage with technology and are able to learn remotely or online. Whilst admissions criteria for SA universities differ from one another, no clear policy pathway that informs and regulates the selection and admissions were established sector wide during this pandemic. Each university has made adjustments to suit their own needs.

3.2.1. Dangling a carrot! - Dealing with admissions. There is a serious concern that the health issues and the economic consequences from the pandemic will result in more students declining admission offers. For this reason, I believe that some universities will be likely to offer students funding or scholarships in an effort to get them to enrol. It is clear that 2021 is a competitive year for student enrolments will be intense. At the end of the day it will be up to students and their parents as to what is the best possible solution for 2021. If a family is affected economically from COVID-19, they may appeal for additional financial aid. The National Student Financial Aid System (NSFAS) provides financial assistance to students who must meet the financial qualification criteria for funding. That is, they must have a combined gross family income of up to R350 000 per annum, as assessed and verified by NSFAS. It is not clear how many households reached this baseline due to COVID-19, since income earned for many families will differ from that of 2019 if parents have lost their jobs and the income has declined. For the 2020 financial year, NSFAS received a record number of first-time applications $(543,268)$ by the 30 November 2019 closing date (compared to 428,929 the previous year) from across the country, with the vast majority of applicants submitting applications online. 


\section{Uncertain futures - It's a matter of time!}

Finally, the challenges facing South African higher education is linked to the wider challenges facing South Africa: poor economic growth, high youth unemployment and the paralyzing effect of the political crisis surrounding the ANC leadership and government. While the South Africa state may have the resources - financial and technical - to map a way forward for the higher education sector, its ability to implement are severely constrained by political leadership and insufficient capacity. (Tjønneland, 2017).

Whilst this pandemic is disruptive and provides little hope it is important to be creative and adaptable to the next normal. Students may not be able to engage as much with staff within the universities, their academic success remains an important factor. Students can learn more about programmes offered by universities by utilising the online platform and resources. Engaging in on line extra-curricular activities within your own spaces following the health protocols can give students the edge to showcase their commitment to learning outside of a formal classroom setting. Leadership skills is a key factor that most universities love to see. Taking initiatives and leading, demonstrating leadership is crucial to post school education. Students must be encouraged to volunteer for social services and engage with communities.

Many students have given consideration to other factors like should they leave their home town, what about the fees if teaching is online and they don't receive a campus experience they have been looking forward to. Most residences at universities have to also rethink how they cater for students ensuring that they adhere to all the COVID protocols. This also means that two students cannot share one room, raising the cost of accommodation for the student. A number of universities have pushed back their application deadline to August and September 2020.

Because of the economic consequences of coronavirus, many students may have to abandon their first choice university to attend one that is more affordable. In addition, a university closer to home would be a more viable choice especially because of fewer accommodation that will be available. (Massa, 2020) Taking these factors into consideration, universities are likely to admit more students than they did last year because they expect that more of their admitted students will ultimately opt to stay closer to home.

Whether to stray from a university choice in these uncertain times is a decision that students and their families must make. At some point - likely long before this entering class graduates from college the pandemic will be over and life as we knew it will return. Parents and students should make this decision carefully, of course, and should consider what is in the student's best interest going forward in a post-COVID world.

How much do we know about the implications for student enrolment, equity, and experience? In a disruptive situation, the main impact will be on persistence, as students will struggle to adapt to online teaching and learning especially those who have not had any access to online teaching. Universities with insufficient methods of creating a captive online experience could be in a less desirable situation is students are dissatisfied with their digital offerings and decide to go elsewhere. Students may wait until the normal campus life begins and therefore many students may take a gap year.

In terms of equity, lower-income students will suffer disproportionately. They are less likely to have the resources, such as laptops and high-speed internet access, to enable them to succeed in an online-learning environment. The most crucial challenge is one of financing their education if they cannot access NSFAS nor can they get bursaries from companies due to the lack of profits during this pandemic year. What of the student campus life and experience, being at home with a laptop or tablet and listening to a lesson is not the same as socializing and going to classes on campus.

When nothing seems normal, and everyone is fighting the pandemic, managing admissions and knowing how to navigate a student experience is daunting. University administrators and academics have to be compassionate and understanding. Students coming to the university for the first time in 2021/22 may be fearful of facing the uncertainty. But if we want to create futures for the incoming class of 2021 and beyond, then a value driven leadership is important to create an environment of care and engagement. After all universities are hubs for innovative thinking and reimagining the future, and in doing so giving opportunities to the leaders of tomorrow. 


\section{References}

Atherton, G, (April, $\left.4^{\text {th }}, 2020\right)$. Admissions and equity challenges for HE post COVID- 19 retrieved on March, 152021 from https://www.universityworldnews.com

Bevins, F., Bryant, J.,Krishnan, C and Law, J. (April, 2020). Coronavirus: How should US higher education plan for an uncertain future? With American campuses largely empty of students, higher-education leaders need to shift their thinking to what happens next. Retrieved on February, 20. 2021 from www.mckinsey.com

Booysen, S. (Ed.). (2016). Fees Must Fall. Student Revolt, Decolonisation and Governance in South Africa. Johannesburg: Wits University Press

Cloete, N, Goedegebuure, L, \& Gornitzka, A. (Eds.). (2016), Pathways through higher education research - a Festschrift in Honour of Peter Maasen, Oslo: Department of Education, University of Oslo

Council on Higher Education, (2016). South African Higher Education Reviewed. Two Decades of Democracy, Pretoria: CHE.

Erasmus, Z. (2010). Confronting the categories: Equitable admissions without apartheid race classification. South African Journal of Higher Education, 24 (2), 244-257.

Gibbon, T, (Ed.). (2014), Driving Change: The Story of the South Africa Norway Tertiary Education Programme, Cape Town, African Minds

Illanes, P and Sarakatsannis, J (2020). Although most students have gone home, colleges and universities still have decisions to make. An integrated nerve center can help. Retrieved on March, 30, 2021 from www.mckinsey.com

Makinana. A. 21 April 2020. Academic year likely to spill over into 2021: higher education ministry. Retrieved on March, 17, 2021 https://www.timeslive.co.za/politics/2020-04-21-academic-year/

Massa,R. (April, 2, 2020) 5 ways that the coronavirus will change college admissions this fall. Retrieved on March, 24, 2021 from https://theconversation.com/5-ways-that-the-coronavirus-will-changecollege-admissions-this-fall-135152

Matsepe D, Michael Cross and Samuel Fenyane (2020). Equity in Admissions Policies of Undergraduate Students in Post-Democracy in Selected South African Universities. International Journal of Criminology and Sociology, 2020, 9, 437-445

Tjønneland, E.N. (2017) Crisis at South Africa's universities - what are the implications for future cooperation with Norway? (CMI Brief vol. 16, no. 3, 4 p.) Bergen: Chr. Michelsen Institute

USAf Board Meeting. (April, 1, 2020). Business continuity in the face of COVID-19 dominates the agenda of the USAf Board of Directors' meeting. Universities South Africa. Retrieved on February, 18, 2021 from www.usaf.ac.za 